\title{
Judging Contemporary Art with Kant
}

\author{
Clive Cazeaux \\ Cardiff Metropolitan University, Cardiff, UK \\ Email: ccazeaux@cardiffmet.ac.uk
}

\begin{abstract}
This article demonstrates the relevance of Kant to the interpretation of contemporary art. The defining properties of contemporary art are the impossibility of definition in material, formal or stylistic terms, and the central role that concepts play in the interpretation of a work. Danto and Osborne suggest how concepts might be applied but they do not develop their proposals. Kant's theory of judgement can provide a fuller account on the basis of the notions of purposiveness and play. The way in which these notions explain the application of concepts to the world, I argue, provides a model of how concepts can be combined to form an interpretation of a work of contemporary art. A detailed example is given.
\end{abstract}

Keywords: aesthetic judgement; contemporary art; interpretation; play; postconceptual; purposiveness

\section{Introduction}

Kant tends to be overlooked as a philosopher of contemporary art. There are a number of contender explanations for this. First, the art at the centre of Kant's theory is eighteenth-century fine art, art that imitates the beautiful in nature (as formulated by Charles Batteux, 2015: 15-18). It is therefore a mode of artmaking that is far removed from present-day practices. Secondly, Kant's theory works on the understanding that the objects of aesthetic judgement are distinctive, that is, examples of the beautiful and the sublime in nature or in art, whereas with contemporary art, the work can be any kind of thing, that is to say, the objects themselves are not distinctive in ways that might be called 'beautiful' or 'sublime'. Thirdly, as Diarmuid Costello has shown, Kant is relied upon heavily by Clement Greenberg in the articulation of his formalist aesthetics (Costello 2007: 94-100). The importance placed by Kant on the form of an object judged (in his terms) to be 'freely beautiful' shapes Greenberg's thesis that the essence of modern art lies in the form taken by a work as a result of properties that are specific to its medium of production, e.g. 'the invention and arrangement of spaces, surfaces, shapes, colours, etc.' achieved by, among others, Kandinsky, Mondrian and Picasso (CPJ, 5: §§16-17; Greenberg 1986: 9). ${ }^{1}$ This association with Greenberg may have prompted many to pigeon-hole Kant's aesthetics as a theory whose sphere of application is limited to modernist abstraction. The only substantial study that

(C) The Author(s), 2021. Published by Cambridge University Press on behalf of Kantian Review. This is an Open Access article, distributed under the terms of the Creative Commons Attribution-NonCommercial-ShareAlike licence (https:// creativecommons.org/licenses/by-nc-sa/4.0/), which permits non-commercial re-use, distribution, and reproduction in any medium, provided the same Creative Commons licence is included and the original work is properly cited. The written permission of Cambridge University Press must be obtained for commercial re-use. 
considers Kant away from taste and formalism and in relation to contemporary art is Thierry de Duve's Kant After Duchamp (de Duve 1996). But de Duve does not seek to construct a Kantian theory of the contemporary. Instead, he focuses on transforming the antinomy of taste into the antinomy of art in order to reach a questionable claim about the conflation of concepts within the Critique of the Power of Judgment. ${ }^{2}$

It would seem, therefore, that Kant's aesthetics is confined to 'the era of taste' within art, and has nothing to offer the art that belongs to 'the era of meaning', to use the periodic terms suggested by Arthur Danto (Danto 2000). I want to challenge this view. I think that Kant's aesthetics is particularly well-suited to addressing contemporary art. This is based on the meaning of 'contemporary'. Although the word might seem to refer unproblematically to the present moment or the present time, its meaning turns out, upon closer inspection, to be more complex, both when taken on its own and when applied to art. Discussion within art theory points to defining properties of contemporary art being the impossibility of its definition in material, formal or stylistic terms (art can be any kind of thing) and the importance of the concepts that are brought to bear upon the work during its appreciation and interpretation. However, there has yet to be a study within aesthetics or art theory that describes how these properties might be understood or exercised in any detailed way. In this article, I demonstrate how Kant's aesthetics can provide a theoretical underpinning for these properties. In keeping with original meaning of aisthessis to refer to what is sensed or felt (acknowledged by Kant; CPJ, 5: 223'), I show how his theory of judgement might be exercised in interpreting a work of contemporary art.

\section{Defining 'contemporary art'}

On the one hand, 'contemporary' is an indexical word: its meaning is dependent upon the context in which it is used, and so it can be employed by a speaker in any period to refer to what is current at that time. On the other, however, the word has been associated in recent aesthetics and art theory with specific meanings centred around conceptual art's impact upon the history of art. It is the latter sense that I focus upon in this article, because it makes claims about the nature of art that might lead one to think contemporary art is beyond the scope of Kant's aesthetics. I want to argue for the opposite: that Kant's theory of judgement is perfectly oriented to address contemporary art, as the term is understood within recent aesthetics and art theory. The former sense is also problematic philosophically in that, as an adjective for art, it leads to the question of whether Kant's aesthetics can apply to the art that is current at the time of utterance. This in turn leads to the questions of how one classifies the art that is current at the time of utterance, and how such a classification might be relevant to Kant. But that is not the enquiry I am conducting. The issues created by pairing Kant with contemporary art in the latter sense, I think, are more compelling, and are of greater relevance to recent writing on the contemporary in aesthetics and art theory.

The nature of contemporary art has received a lot of attention within aesthetics and art theory. Many of the accounts share the view that 'contemporary' has been adopted to signal the turn away from the modern era's emphasis on medium-specific practice and the turn towards conceptual art's exploration of the space opened up by the readymade and the removal of any limit on the form art can take. This view can be found in Osborne (2013), Rajchman (2011) and Smith (2006). There is also the question of the 
contemporary nature of an artwork when asked from a hermeneutic perspective. The interest here, as Gadamer explains, is not in the artwork as an index or expression of a moment but in aesthetic understanding as a process that involves 'bring[ing] together two moments that are not concurrent, namely one's own present and ... [another from the past]' (Gadamer 1989: 127-8). The ambition with such understanding is to mediate the two events so that the past event 'is experienced and taken seriously as present (and not as something in a distant past)' (Gadamer 1989: 127-8).

Beyond these two definitions, there are two further proposals which claim that a more philosophically demanding predicament is at the root of the concept of the contemporary. Common to both is the idea that at the heart of contemporaneity lies the question of judgement, in a sense that is close to, or not remote from, Kant's understanding of the term. The first predicament is set out by Giorgio Agamben. Although Agamben does not consider the contemporary in relation to art, he does present a viewpoint that invites application to it. Agamben takes inspiration from Nietzsche when he declares that 'to be contemporary is to be untimely' (Agamben 2009: 40). Agamben has in mind Nietzsche's Untimely Meditations (Unzeitgemässe Betrachtungen), published in 1874, in which he advocates the perception of the historical culture that shapes one's time as 'an illness, a disability, [or] a defect' (Agamben 2009: 40). To be untimely, to be contemporary, is to treat the values and conventions of one's time as disabilities with which one is also afflicted but where one is at least aware of the affliction. It is because of this awareness, Agamben suggests, that the untimely person is able to grasp the characteristics of their time; the timely person cannot perceive the ways in which history infects their age because their pride in their historical culture blinds them to its symptoms and effects. So, for Agamben, to be contemporary is to be sensitive to disease and disability, not necessarily in a narrow biological sense, but in an ethical sense (which can be regarded as a broad biological sense, as in the logic of life) in that one is sensitive to what is working against the greater social good.

The second philosophical predicament at the root of contemporary art is given by Peter Osborne. According to Osborne, contemporary art is 'postconceptual art', where 'post' refers not to a particular kind of art or one kind of art that follows another (as if such a line could be easily drawn) but instead to 'the complex historical experience and critical legacy of conceptual art, broadly construed, which registers its fundamental mutation of the ontology of the artwork' (Osborne 2013: 48). I think there are three key meanings to extract from this. Postconceptual art: (i) pursues conceptual art's rejection of the traditional art-historical concepts of medium, form and style; (ii) explores the ontological 'expansion to infinity of the possible material forms of art' or the fact that art can be any kind of thing (Osborne 2013: 48); and (iii) given the rejection of traditional categories and the infinite expansion, demands that care is taken in determining the conditions under which individual works of art are interpreted, especially the choice of concepts that are brought to bear upon a work. Of the three, it is points (ii) and (iii) that are the most significant, since they affirm the difficulties of coming to terms with art after the readymade; (i) is essentially a restatement of the point made at the start that the 'contemporary' in art signals a turn away from the modern era's emphasis on medium-specific practice. Points (ii) and (iii) also bear some comparison with Arthur Danto's assertion that, after the readymade, 'to see something as art requires something the eye cannot descry - an atmosphere of artistic theory, a knowledge of the history of art: an artworld' (Danto 1964: 580). With 
institutional endorsement of the gesture which allows any kind of thing or event to be baptized as art, the 'possible material forms of art' expand to infinity, and the artness of a work becomes a matter of interpretation, which will inevitably draw upon concepts from art history and theory.

\section{The role of concepts in contemporary art}

Far from remaining merely as a list of questions concerning the contemporary in art, the topics just outlined in actual fact overlap one another in a way that allows the formation of two principal questions that invite a Kantian response. First, although it is now accepted that art can be anything, i.e. any kind of thing - captured in Osborne's 'expansion to infinity of the possible material forms of art' - the question remains of how the object or event presented as art can be understood or interpreted as such. The question is implicit in the importance attached by Danto and Osborne to determining the conditions under which individual works of art are interpreted, including the choice of concepts that are employed in the interpretation. The question may also be taken as a form of Gadamer's interest in what happens when 'two moments that are not concurrent, namely one's own present and ... [another from the past]' are brought together in a way that the past is 'taken seriously as the present', where the two moments might be the concept of art and the object or event that is offered as a candidate for appreciation (Gadamer 1989: 127-8).

The two main responses to this predicament within philosophical aesthetics from Danto and Osborne again - both involve turning to the way in which concepts might be applied to the objects offered for appreciation as a solution. Initially, as I note above, Danto asserts that we need 'an atmosphere of artistic theory, a knowledge of the history of art: an artworld' (Danto 1964: 580), but he does not state precisely how a knowledge of art history might be put to use in dealing with an object that bears no relation to art's history. This is the problem that Gadamer raises. Danto's more detailed response comes in 1981 in The Transfiguration of the Commonplace when he asserts that the conceptual-historical process exercised by the artworld in accepting readymades as art is an act of transfiguration achieved through metaphor: 'to understand the artwork is to grasp the metaphor that is always there ... The middle term has to be found, the gap has to be filled in, the mind moved to action' (Danto 1981: 171-2). The readymade is a 'brash metaphor' of the order 'the brillo-box-as-awork-of-art' (Danto 1981: 208). That is to say, calling it a work of art performs the action of metaphor that is always present in art, typically through the process of seeing-as, seeing one thing as another, for example, the way in which Roy Lichtenstein's painting Portrait of Madame Cézanne, which resembles a diagram, invites us to view Madame Cézanne in a diagrammatic mode.

The way in which concepts might be applied to the objects offered for appreciation is also central to Osborne's theory of contemporary art or, as he terms it, postconceptual art. One of the main aspects of postconceptual art, for Osborne, is the need for care when determining the conditions under which individual works of art are interpreted, especially the choice of concepts that are brought to bear upon a work. This is evident in his affirmation of 'art's necessary conceptuality' (the fact that 'art is constituted by concepts, their relations and their instantiation in practices of 
discrimination: art/non-art'), its necessary aesthetic dimension (the fact that 'all art requires some form of materialization' which calls for interpretation), and that 'a productive act of imagination [is required]' in order to project 'a non-existent unity onto the disjunctive [social] relations between coeval times', that is to say, calling artworks that have been produced in recent, coeval times 'contemporary' is an act of narrative unity that brings together the manifestations of what are otherwise contrasting milieus and subject-positions (Osborne 2013: 23, 48). The concept that Osborne offers to guide us in making these careful acts of interpretation is 'transcategoriality': a movement across or between categories as a range of concepts are summoned and brought into contact with one another - some from art history, others from the social and cultural spaces inhabited by art - as they struggle to come to terms with the various forms that art might now take (Osborne 2013: 48). However, the nature of such transcategorial movements - what they look like and what their implications might be - is not set out by Osborne, beyond the suggestion, via brief references to Heidegger and Adorno, that the power of some works of postconceptual art lies in their generation of possibilities (Osborne 2013: 171-2). Examples given of postconceptual artworks include Smithson's Spiral Jetty (1970), because it is 'a complex distribution of artistic [and non-artistic] materials, across a multiplicity of material forms and practices, the unity of which constitutes a singular, though internally multitudinous work' (Osborne 2013: 110), and the installation We Can Make Rain But No One Came to Ask (2006) by The Atlas Group (a pseudonym for the Lebanese-American artist Walid Raad), on account of its combination of philosophical critique, fictionalized narrative, video, split screens and multiple soundtracks (Osborne 2013: 200). But the accounts of the works are merely verifiable descriptions of the various elements that they contain. We are not given an explanation of how they function as sites of transcategorial movement or interaction.

\section{The relevance of Kant's theory of judgement}

Kant has something to contribute in terms of fathoming the application of concepts to contemporary art, I think, because the question of the application of concepts to an aesthetic encounter whose openness to conceptualization is unknown is at the centre of his theory of judgement. ${ }^{3}$ This happens in two ways within his critical philosophy: the concept-intuition relation, and the encounters with beauty, fine art (that imitates beauty) and aesthetic ideas that summon the concept of purposiveness (Zweckmäßigkeit). Both are forms of 'coming to terms with what is before us', and quite literally so, since Kant's critical philosophy rests upon the idea that experience has to be experience of something, that is, it has to be interpreted as possessing a specific character. If experience of the world is formulated in terms of concepts within a human subject determining sensory intuitions, then some account has to be given of the process whereby concepts are able to interlock with intuitions and determine them in a more-than-subjective way. The concept of nature's subjective purposiveness is at the centre of Kant's explanation.

Purposiveness is the appearance of design or purpose in a thing or an environment without there necessarily being a design or purpose in operation. It is the idea that the world appears to us as if it had been designed for our awareness. In the context of the third Critique, the concept plays a decisive role in enabling Kant to complete his 
theory of judgement, first introduced in the Critique of Pure Reason, and to clarify the relationship between reason and nature that is exercised in different ways across the first two Critiques. Purposiveness is the transcendental assumption that allows judgement to bring the diversity and contingency of nature under unifying concepts and thereby to form experience. The concept occurs in judgements about art in Kant's philosophy (a) because aesthetic judgements are reflective judgements in need of a concept, and (b) because, in eighteenth-century Europe, fine art is art that imitates the beauty of nature. 'In [dealing with] a product of fine art', Kant asserts, 'we must become conscious that it is art rather than nature, and yet the purposiveness [the appearance of design or purpose] in its form must seem as free from all constraint of chosen rules as if it were a product of mere nature' (CPJ, 5: 306). Reason (a) is derived from the need to provide a theory of judgement that is coherent with regard to the principle 'all judgements require a concept', while reason (b) follows from Kant's working in accordance with the eighteenth-century, European concept of art. However, it is not purposiveness as summoned by the imitation of beauty (reason b) that I want to pursue. It is rather purposiveness as the concept that explains how the experiencing subject gets a grip on the world conceptually (reason a) that I think is more relevant for contemporary art. Purposiveness, Kant writes, is the principle that

we must think nature, as regards its merely empirical laws, as containing the possibility of an endless diversity of empirical laws that [despite being laws] are nonetheless contingent as far as we can see ... and it is in view of this possibility that we judge the unity of nature in terms of empirical laws, as well as the possibility of the unity of experience ... to be contingent. And yet we must necessarily presuppose and assume this unity, since otherwise our empirical cognition could not thoroughly cohere to [form] a whole of experience .... (CPJ, 5: 183)

This is the claim that it would be impossible for our understanding to discover in nature an order it could grasp (fassen) - i.e. impossible for it to divide nature's products into genera and species', if judgement did not engage with nature in such a way that its application of concepts corresponded with divisions in nature. The component of judgement which allows this to happen is the state of free play between the faculties of the imagination (which combines and presents the manifold of intuition) and the understanding (which provides concepts) (CPJ, 5: 217-18). The nature of the free play, and its role within Kant's architectonic, continue to be subjects of Kantian scholarship (see e.g. Ginsborg 1997; Guyer 1997; Rush 2001). I do not propose to enter the debate or to introduce a novel account of the process here. My interest in the free play is purely to the extent that it is an occasion where, according to Fred L. Rush Jr., 'the imagination's activity is to survey the [sensory] manifold and "pose" or "suggest" different ways in which it might be arranged' (Rush 2001: 56). On this reading, free play is the process that creates the variety of could-be-this, could-be-that options within purposiveness that, in turn, enables judgement to get a grip on nature. It is the idea of a number of concepts being brought reflectively to a manifold in an attempt to make sense of it that I think is important. I shall return later to the question of how we might picture the process in operation when I offer an example. 
Contemporary art, with its condition of making us uncertain how to apply concepts, I propose, puts us in a situation where we are obliged to reflect on the possibility of judgement. Just as the enabling condition for Kant is a state of free play in which the understanding is able to intersect with sensibility, so I want to argue that the state of being confronted by a work of contemporary art is one in which we begin to play with combinations of concepts in a judgement as a way of interpreting the work. In this regard, I am following Kant's use of eighteenth-century fine art as a form that gives him the opportunity to introduce reflective judgement and, therefore, the additional apparatus that allows him to reconcile freedom and nature. It is just that I am reversing the relation: instead of using art to expand upon the conditions of possibility of judgement, I am using the conditions of possibility of judgement to expand upon how contemporary art is understood. I am taking the fundamental question of how it is possible for human cognitive capacities to mesh with the diversity of nature as the model of what it is like to come to terms with a work of contemporary art. Both Danto and Osborne characterize the condition of contemporary art as one in which we are presented with a work to which no modern artistic concepts apply, yet which demands interpretation through the introduction of concepts. It is just that the manner of the introduction, beyond brief references to metaphor (by Danto) and transcategoriality (by Osborne), is not developed. I think purposiveness can assist us here because the encounter with contemporary art is one in which we are not sure how to begin, and so we are thrust into a situation where we have to play with concepts to see which combinations might afford us a grasp of the work.

\section{Aesthetics and ethics}

The second question that I think can be extracted from the various definitions of the contemporary is how a work of art that claims to be contemporary can encourage some critical distance from the culture that led to its production. This comes from Agamben's emphasis on perceiving the values and conventions of one's time as disabilities with which one is afflicted. It is also present in Osborne's assertion that the critical capacity of contemporary art is driven by the ontological uncertainty that surrounds it, i.e. the fact that it is no longer just painting or sculpture but can now be any kind of thing. Osborne writes:

If art is to function critically within [art] institutions ... it must relate directly to the socio-spatial ontology of its own international and transnational sites and relations. It is at this point that the critical historical significance of the transformation of the ontology of the artwork ... comes into its own. (Osborne 2013: 27-8)

This critical significance 'comes into its own' for Osborne in the sense that any work of contemporary art demands to be addressed as a specific work and not as a specific kind of work. The idea that artworks might be of a kind, where that kind is described by traditional art-historical and art-critical concepts, such as medium, form, style, representation and expression, he argues, has passed. Art continues, and continues to involve drawing upon and engaging critically with historical concepts of art, but it is just that, now, none of the concepts fit. Osborne's response to this predicament 
is the concept of transcategoriality, introduced above (Osborne 2013: 48). Unfortunately, quite how a movement across categories - summoned and brought into contact with one another in an attempt to come to terms with the various forms that art can now take - generates critical distance within a culture or institution is not spelt out by Osborne.

I think Kant's aesthetics can go some way to explaining how contemporary art might create critical distance from an institutional or cultural setting, as asserted by Osborne in relation to art and by Agamben in relation to culture. The proposal can be taken as an ethical one, since it asks after the possibility of thought and action that are not bound or prevented by the values and conventions of one's milieu. This is ethical in the sense that value is accorded not just to practices that currently exist but also to those that have yet to be brought into being, where the novelty might yield improvement, an awareness of freedom or the emergence of a new mode of conduct or life that has the potential to be beneficial for many. The relevance of Kant is signalled by his claim in section 59 of the third Critique that beauty is the symbol of morality, by which he means that beauty is an analogy for morality. ${ }^{4}$ An appeal to beauty might sound odd in the context of a debate on contemporary art which in no way aims to reproduce beauty in nature. But it needs to be remembered that it is not so much beauty itself but the purposiveness that it elicits in the experiencing subject that is the core of the analogy. The universality displayed by aesthetic judgements (they are claims that command agreement from everyone) derives from the reflective concept of nature's subjective purposiveness, which in turn refers 'to something that is both in the subject themselves and outside them', namely, the super-sensible substrate underlying both nature and (more importantly here) the freedom that enables moral thought (CPJ, 5: 353). This is, of course, a summary that requires exposition and defence, neither of which will be given here, as the focus on Kant and contemporary art needs to be maintained.

My thesis is that a theory of contemporary art, understood in the 'ethical' sense of contemporary, can be found in Kant independently of any reference to beauty on account of the position that purposiveness occupies within the theory. Of the various studies that argue for an analogical link between Kant's aesthetic judgement and his moral philosophy, my thinking is most closely aligned to that of R. W. Gotshalk (1967). According to Gotshalk, the analogy between taste and morality is at its strongest in the terms used by Kant to characterize the unbounded nature of aesthetic ideas. 'Since the moral life has a similar aspiration towards achievements of infinite [or unbounded] quality', he argues, nature expressed through aesthetic ideas in art therefore can be regarded as presenting 'evidence of a congruence between its [nature's] being and the laws and powers properly guiding our conduct in the realm of freedom' (Gotshalk 1967: 258). The relation between aesthetic judgement and morality as it occurs in the case of contemporary art, I suggest, manifests itself most strongly in terms of the boundlessness into which we are thrown when trying to get to grips with the objects that make up a work. The state of boundlessness requires us to make sense of what is before us in the absence of any determinate signs. It is a state that involves the transcendental assumption of purposiveness, for only in this way is judgement able to bring the diversity and contingency of what is presented to it under a play of possible concepts and, thereby, to form an experience of the work. Furthermore, our act of making sense of the work is one that would need to be 
recognized by others as an attentive reading. Our situation is therefore comparable to a moral one in which we, as beings with freedom of will, strive to act in a way that could become a universal law.

\section{Purposive play}

What my emphasis on purposiveness brings to light is the importance of the play of concepts in the appreciation of art. These are concepts that are applied not determinatively but reflectively; they are not determining the nature of the object in front of me but exploring how concepts might be combined with one another in such a way that the artwork opens up to me for a fuller appreciation. Although purposiveness is the concept that completes Kant's explanation of how judgement is able to intersect with nature determinatively, it is a principle of reflective judgement, which is to say that it refers to the act of judgement itself and not to the object judged. This means the value of purposiveness as a concept that might apply to the appreciation of contemporary art is two-fold: (i) it emphasizes the play of concepts that is involved in coming to terms with the work, and (ii) it encourages a context in which the aim of interpretation is to open up a work, that is, to enlarge the number of ways in which it might be interpreted.

There are arguably two contexts in which play occurs in the third Critique: the play that is occasioned by perceiving beauty in nature and in fine art (e.g. CPJ, 5: 217-18), and the play that is generated by the imagination's autonomous presentation of aesthetic ideas (e.g. CPJ, 5: 313). Despite this difference in setting, both forms of play are purposive in that they involve the interplay of the faculties necessary for judgement. The key point here is that perceiving beauty in nature and being presented with aesthetic ideas occur as aesthetic judgements. While we have become accustomed to using 'aesthetic' to refer to judgements of art and beauty, it needs to be remembered that Kant is building upon the eighteenth-century change in the meaning of aesthetic, from sensation to feelings of pleasure and displeasure, and making it apply to the power of judgement. More importantly, he has it refer to the capacity of the subject to sense the interplay between the imagination and the understanding that enables judgement as pleasure, thereby retaining some contact with the original meaning of knowledge obtained via the senses (CPJ, 5: 223').

Despite this emphasis on being able to sense the interplay of our cognitive faculties, Kant has little to say on what the play might actually look or feel like. The only indications given are that there is the generation of 'inner intuitions to which no concept can be completely adequate' (CPJ, 5: 314), the prompting 'of so much thought as can never be comprehended within a determinate concept' (CPJ, 5: 315), a presentation 'that prompts the imagination to spread over a multitude of kindred presentations that arouse more thought than can be expressed in a concept determined by words' (CPJ, 5: 315), and 'the opening up ... [of] a view into an immense realm of kindred presentations' that 'quicken[s] the mind' (CPJ, 5: 315). Scholars and students of Kant will be familiar with these phrases. But what does 'the opening up ... [of] a view into an immense realm of kindred presentations' look like? Most of the work on free play within Kantian scholarship concentrates upon whether it can sit coherently within Kant's theory of judgement, since, as Hannah Ginsborg makes the point, it amounts to the claim that the "imagination displays the "regularity" and "lawfulness" 
associated with understanding (CPJ, 5: 296, 241); yet, the regularity or lawfulness is "free lawfulness" or "lawfulness without a law" (CPJ, 5: 240, 241)' (Ginsborg 1997: 67). One account that does offer a description of the activity of free play is given by Rush. He suggests that

what Kant envisions is a potentially endless ranging over the manifold of intuition by the imagination, engaged in the activity of modelling it as unifiable in any of the multifarious ways that the spatial and temporal properties of that manifold permit ... [W] hile it is true that any given manifold will not permit just any imaginative modelling of it (for instance, the form of a moth cannot plausibly even fleetingly be modelled on the order of a mountain), any beautiful thing will permit a seamless, effortless, and potentially endless series of unconscious 'reimaginings'. (Rush 2001: 58)

On Rush's view, 'the opening up ... [of] a view into an immense realm of kindred presentations' involves the imagination seeking ways in which the sensory manifold might be modelled or unified in preparation for conceptualization. I would add that the acts of modelling or unifying are assisted by concepts in a preparatory or reflective (but not a determinative) mode, since concepts are Kant's principles of unity. I take this to be consistent with Kant's claim that aesthetic judgement 'contains a principle of subsumption' but 'this subsumption is not one of intuitions under concepts, but, rather, one of the power of intuitions or exhibition (the imagination) under the power of concepts (the understanding)' (CPJ, 5: 287; original emphases).

I think the description from Rush is helpful, but I want to make two linked qualifications. First, although he calls the unities produced during free play 'apprehensive' or 'proleptic unities' (Rush 2001: 56), the pleasure of aesthetic judgement lies in not in arriving at a final, conclusive determinative judgement (the one that is being anticipated) but in the many possible, apprehensive meanings that are generated within the free play. Secondly, he states that 'any beautiful thing will permit a seamless, effortless, and potentially endless series of unconscious "reimaginings"' (Rush 2001: 58 ; emphasis added). While we may not be conscious of the unities one-by-one, with the clarity of individual cognitive, determinative judgements, their occurrence as a playful sequence will nevertheless be felt; this is the pleasure that is created by the free play of the faculties (CPJ, 5: 217). In what follows, I propose to slow this process down and to describe what such a playful activity in relation to a work of contemporary art might be like. Although Kant's aesthetics are conventionally taken to apply to beautiful artworks and objects (asserted by Rush above), my claim is that something similar can be seen to occur when we ponder a work of contemporary art. If its level of borrowing from everyday life and the uncertainty of its context leave us bewildered, then we need to allow our faculties to enter a state of free play. An array of thoughts will occur in no particular order. Different aspects of what is before us sensorily will be made prominent as different concepts are introduced to see what might arise from the pairing. I shall write the thoughts down. Despite my 'no particular order' claim, there will be some order, typically the order of sentences that follow conventions of structure and the elaboration of themes. But they will also be playful in the sense that combinations of concepts are sought purely in the interest of creating aspects that allow meaningful judgement to occur. This could be said to constitute an aesthetics 
of judgement in the original sense of aisthessis, in that the play of ideas that occurs as one tries to come to terms with the work is laid out in space and time, and we get to see the formation of different paths of access to the work.

\section{Interpreting Ceal Floyer's Monochrome Till Receipt (White)}

I have opted for an artwork that meets the criteria outlined above for Osborne's postconceptual art: (i) it pursues conceptual art's rejection of the traditional art-historical concepts of medium, form and style; (ii) it explores the ontological 'expansion to infinity of the possible material forms of art' or the fact that art can be any kind of thing (Osborne 2013: 48); and (iii) it demands that care is taken in selecting the concepts that are applied to it in the process of interpretation. The work is Ceal Floyer's Monochrome Till Receipt (White) (Figure 1) from 1999: a till receipt from Morrisons, a United Kingdom supermarket chain, that lists forty-nine items purchased from the chain's Camden store by Floyer that are either white or have 'white' in their name, such as flour, hand cream, white kidney beans, Glowhite stain remover. The receipt is pasted to the wall directly without an overt framing device, beyond the fact that a large amount of space is left on either side of the receipt. This creates a scene in which there is a large area of white wall at the centre of which is a tall, thin, yellowish-white column. Forty-nine items were bought, so the receipt is long.

The best way into describing an encounter with a work of contemporary art in the light of Kantian purposiveness is to emphasize the feeling of being lost that arises when one stands before the work. Where does one begin? How does one begin? How do I bring concepts to bear on the work in order to appreciate the object as art? The situation is one where we have to reflect upon the concepts that are to hand and might be drawn upon in creating a meaningful encounter. Concepts will be available because I am an embodied being; the concepts I use to make sense of physical space and different kinds of environment will be present. I know many customs and conventions of late twentieth-, early twenty-first-century life in the United Kingdom and the modern Western world, so I recognize a till receipt when I see one. The fact that the receipt is installed in an art gallery means that concepts from the history of art are also within reach. I might know something of Ceal Floyer's work, her interest in magnifying small or overlooked details of everyday life and then pursuing them in surprising ways. But this will not necessarily introduce concepts that exceed what is in front of me, as a till receipt that has been placed at the centre of a gallery wall is already a small detail of everyday life that has been enlarged and pursued in a surprising way.

There is an accompanying, explanatory caption panel. Because it is similar in form and scale to the receipt and would compete with it for attention, the panel is placed some distance from the receipt. I could read the caption. To do so would introduce a series of ideas and observations to my thoughts, some of which will cohere with or be evident from what is on view, while others will offer background, context and possibly an artworld narrative that are not necessarily readable from the receipt and its position. I choose not to read the caption, beyond reading the title. This is so that priority can be given to the play of concepts that comes from addressing the work in terms independently of an artworld narrative that might (not necessarily limit but) affect or direct the play of concepts that is to follow. The title, as we shall 


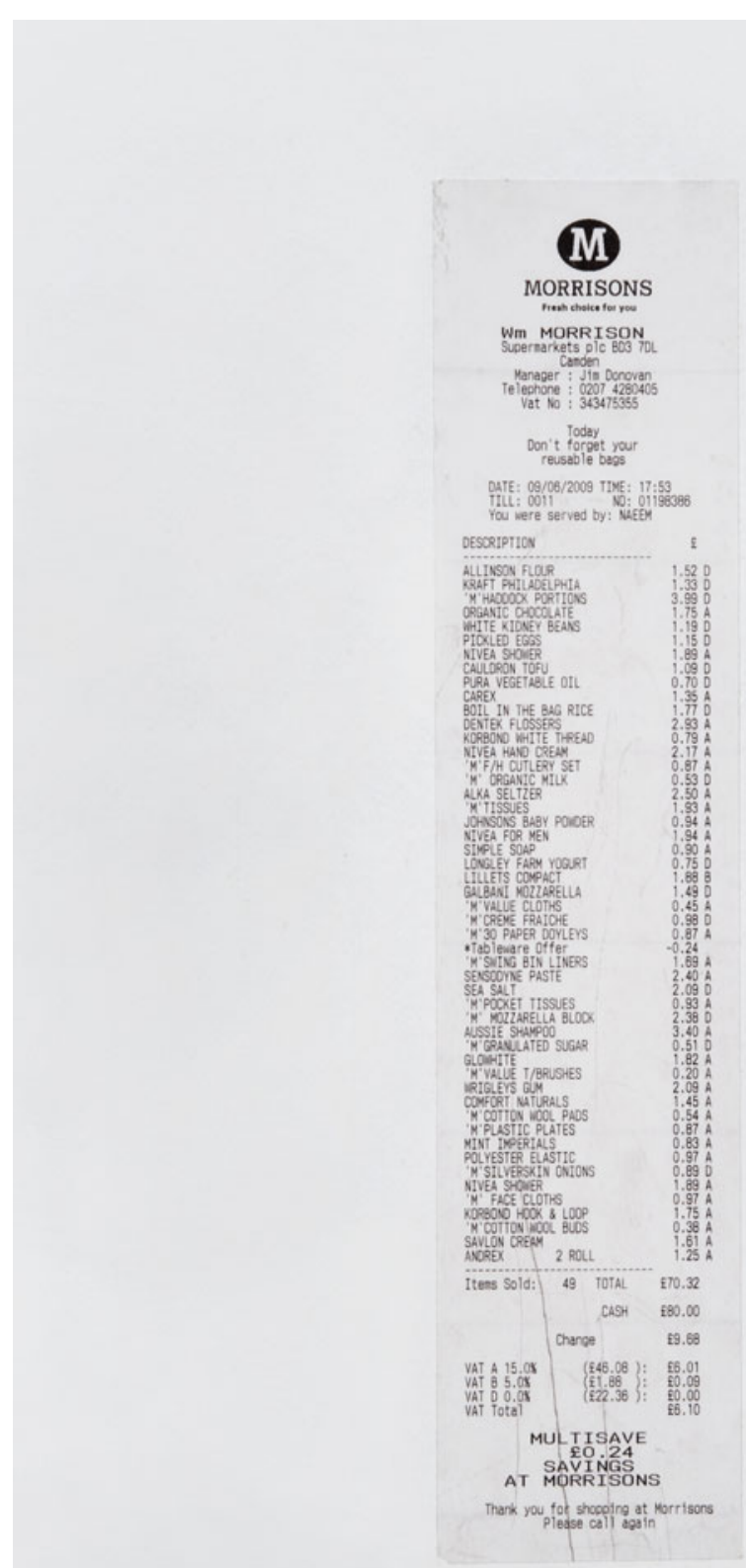

Figure I. Ceal Floyer, Monochrome Till Receipt (White), 1999. Ink on paper on wall, $80 \times 393 \mathrm{~mm}$. ( Ceal Floyer, courtesy Lisson Gallery, London. 
see, is decisive, and could be described (with the pun fully intended) as a key player. (I include the caption in this endnote..$^{5}$ It declares that all the items on the receipt are white and purchased by Floyer, and provides some limited art historical information regarding readymades, some prompts for thought and (possibly) a quotation from the artist. While the first two elements constitute helpful information, the last two actually direct attention away from the artwork. As a result, there is nothing in the caption that immediately presents itself as a theme that would govern interpretation.)

The first thought is incongruity. A large expanse of wall in a gallery at the centre of which is a long, vertical strip of yellowish-white paper. It bears lines of text. It is a list. It is a till receipt. The incongruity comes from the fact that it is not the kind of object one would expect to command such space in a gallery. It is not a matter of the kind of object that has been placed on the wall; readymades are regular occurrences in the artworld now. It is that something so insignificant should occupy such space, should hold such power. There is no frame; nothing to reinforce the object or help to call attention to it. There has been no attempt to enlarge the document, to make the text legible from a distance. It could easily be missed were it not for the fact that it has the look of an error, something left behind by the personnel responsible for maintaining the gallery. One can see that it is a receipt from a distance but has to move in close to make out the text. As well as its position of authority, it is a receipt that is suspended, fixed and upright. Something that would normally be held, folded, placed in a wallet or purse or discarded, is now part of the surface of a building. Roles have been reversed. I cannot hold, fold or dispose of it as I see fit. I have to move in relation to it. I have to stoop slightly if I want to read lines at the bottom of the strip.

Then comes the flip when it is recognized that we are being asked to entertain what a till receipt becomes when it is assigned such power. Every detail changes. With the slight trace of an everyday, unremarkable event being given such a position, one wonders whether it is an invitation to perform or to participate in a new, related event within the space that it commands in the gallery. Are the purchases intended to be the ingredients for a meal or a gathering? The meal in art brings many associations. I know that the presence of the receipt means that the event may have already happened somewhere else, but I am uncertain whether its presence is an invitation to reconstruct an event or an instruction to ponder what I might have missed. The name of a supermarket chain (Morrisons) suddenly acquires a weight. I'm not sure what kind of weight, but the name runs several times in my head. Van Morrison and Morrissey come to mind. Might the lines be song lyrics or a setlist for a concert? The white $\mathrm{M}$ on a black circle becomes akin to the $\mathrm{S}$ of Superman.

These thoughts are a preface to the play that comes from the list of purchases. Two lines of exploration vie for attention at this point. First, the title of the work becomes prominent in my thoughts in the hope that it might provide a clue to the theme or purpose behind the list. Monochrome Till Receipt (White). Monochrome and White, albeit with the 'white' in brackets. So colour is important. But does 'monochrome' refer to the black ink of the receipt or to the white in brackets? Scanning the list reveals that many - no, all - of the purchases are white or near-white in colour: flour, haddock, white kidney beans, etc. The receipt now stands as the trace document of a particular event: the artist (one presumes) selecting all the white items she can find in a supermarket. The range of actions and events that could follow from acquiring such items collides with my standing before a minimal document in a white space. On the one 
hand, the two situations could not seem more remote: the cooking, laughing, cleaning and living that unfold from these objects versus an occasion in which a gallery visitor is left hesitant in a space which has had virtually all signs of life removed from it. On the other, there is the beautiful interplay between the event and its trace: a visit to a supermarket governed by the avoidance of all colours except white that creates as its record an insubstantial token that is itself predominantly white in a space that is white. Two events choreographed by slender means.

The second line of exploration departs from knowledge of the receipt as the index of an action. When lines of text in a vertical column are placed in an art context, it is difficult not to want to entertain them as poetry or wordplay. The potential is too great to resist. I begin to devise rules. Only allow combinations of words from consecutive rows. Powder men simple. Compact mozzarella cloths. Block granulated Aussie. Combinations from every other row. Cream loop shower. Bin doyleys' value. Tissues for yogurt. Such an approach, it could be argued, reduces the work to a text and dismisses its aesthetic, physical form as a till receipt on a wall. But this would be to forget that reduction is part of the nature of the work, and to play with the words on the receipt is to enjoy the freedom that has been granted by a larger event being pared down to a few short lines on a strip of paper.

It might seem odd that, in an article that claims to be judging contemporary art with Kant, no specific reference is made to him in the interpretation of Floyer's work. The reason that neither his name nor any of his concepts appears in the interpretation is that the entire description of the work is offered as an example of Kantian purposive play in operation. An epistemology based upon play eventually has to let the process play out. Given this point, it could still be objected that play is a general concept and, while introduced to modern aesthetics by Kant, it is also present in ancient aesthetics (Kidd 2019) and has been developed by post-Kantian thinkers, e.g. Schiller's play drive (Spieltrieb; Schiller 1993) and Nietzsche's concept of the artwork as a play of forces (Nietzsche 1999). As such, I could be open to the criticism that all I am providing is a theory of judging contemporary art through playful interpretation, and not an account of judging in Kantian terms. But this would be to overlook the vital point that play is integral to purposiveness for Kant. In terms of his theory of judgement, free play is the process that creates the variety of could-be-this, could-bethat options within purposiveness that enables judgement to get a grip on nature. In relation to contemporary art, the absence of any limit on its material form and the frequent absence of any context for the forms presented means the encounter is one in which we are not sure how to begin. This, I am claiming, puts us in a situation where we have to begin playing with concepts to see which combinations might afford us a grasp of the work. Kant and his terminology might not appear but the play of concepts that occurs is a display of how they might be combined with one another in such a way that begins to open up the artwork for appreciation.

I am effectively claiming there is something distinctive about Kantian purposive playfulness that needs to be recognized within a broader understanding of the role of play within aesthetics. The concept is widely discussed and is shown to hold meanings attached to ambiguity, gaming, make-believe, metaphor, the exercise of power and modes of being that depart from reason (see e.g. Spariosu 1989; Sutton-Smith 1997). I do not have the space to say in detail how or where Kantian purposive play might stand within the taxonomy of the subject, but can say briefly that it is 
characterized by an attentiveness to what is presented by the senses, and to ideas that might stretch the applicability of a concept (recalling Kant's references to concepts being expanded and reason being made to think more (CPJ, 5: 315)). It is for these reasons that the aesthetic judgements made in response to Floyer's Monochrome Till Receipt (White) never stray too far beyond what is visible on the wall (or page or screen), and the ideas they contain are pondered in such a way that they explore, and arguably stretch, the meanings that might be drawn from the work.

\section{Conclusion}

Kant's aesthetics deserves to be acknowledged as a framework that is particularly suited to addressing the unbounded nature of contemporary art. A theory that outwardly addresses art from 'the era of taste' turns out to involve a fundamental process that makes it perfectly equipped to handle art from 'the era of meaning', to recall Danto's periodic terms (Danto 2000). Kant's philosophy makes central the predicament of concepts seeking to get a grip on the world, and the encounter with art is formulated as an experience in which the subject feels, i.e. becomes aware of, a free play of the faculties in which 'a multitude of kindred presentations' stimulate more thought than can be expressed in a single concept (CPJ, 5: 315). The focus on the play of concepts stems from ideas given by Danto and Osborne. However, the nature of transcategoriality is never spelt out by Osborne, and Danto's reference to metaphor only goes so far as to suggest that we see the readymade as a metaphor. The kind of conceptual leaps that might be performed by the readymade-as-metaphor are not considered. The irony is that Danto, in the text where he presents his theory of art as metaphor, dismisses Kant for his 'insensitivity' to art. He is, Danto avers, one of the philosophers who has done the most to write 'about art in abstraction from the wider conceptual matrices in which in fact and probably in principle it has always been embedded' (Danto 1981: 55). However, Kant's abstraction, I think, can be highly sensitive to contemporary art. A Kantian perspective emphasizes the importance of having to find concepts, and that the process is not one of trying to find the answer - how many times has 'What does it mean?' been asked in a hushed tone in a gallery? - but one in which the playful combination of concepts in judgements is encouraged as part of the dance that is art appreciation. To rephrase this claim in less technical language, it takes the sense of loss or bewilderment that often accompanies viewing contemporary art and turns it into an occasion for pleasure as a result of the attempts that are made to come to terms with the work.

It might be objected that this approach returns contemporary art to being a kind of early twentieth-century formalism, treating the artwork as an object to be appreciated wholly in terms of its formal, aesthetic properties, with no consideration given to how the work might address cultural contexts. Such a criticism misses the mark, however. It fails to acknowledge that many of the judgements I make about Monochrome Till Receipt (White) involve combinations of concepts whose meaning involves engagement with practical or cultural settings. The experience of how an event and its transformation within a gallery can both unfold from an insubstantial object and its position on a gallery wall is one that affects understanding of how space is organized, and how connections between spaces can be formed by objects. This is an understanding that can motivate or guide action in the world. The criticism also suffers from 
treating playfulness - and especially a playfulness born of the subjective state of exercising judgement - as a lack of seriousness, but this is a mistake. Play and seriousness are not mutually exclusive. This is particularly the case for Kant, for whom play is an act of becoming aware of one's capacity to judge, and within that the freedom that allows the human subject autonomous moral action. As I have indicated, the cogency of the aesthetics-ethics claim is already the subject of Kantian scholarship. My interpretation of Floyer's work does not include any judgements that could be said to constitute an ethical reading. But to carry such an expectation is to misunderstand what is implied by a relationship between the aesthetic and the ethical in the third Critique. It is ethical freedom that is glimpsed, not a specific, fully formed ethical statement.

Bringing Kant to bear on the nature of contemporary art in this way is not just a matter of using his theory of judgement to supplement a couple of proposals on the application of concepts from Danto (in relation to metaphor) and Osborne (transcategoriality). The implications are more far-reaching. As I have already said, I am reversing the relation between art and philosophy in the third Critique: instead of using art to expand upon the conditions of possibility of judgement, I am using the conditions of possibility of judgement to expand upon how contemporary art is understood. I am taking the fundamental question of how it is possible for human cognitive capacities to mesh with the diversity of nature as the model of what it is like to come to terms with a work of contemporary art. Far from reducing contemporary art to a narrowly conceived formalism, it presents it as an occasion where we are invited to play and, in so doing, to reflect upon the capacities that allow us to know and to act freely within the world. ${ }^{6}$

\section{Notes}

1 CPJ, 5, refers to Immanuel Kant, Critique of the Power of Judgment, trans. Werner S. Pluhar. Full details are given in the references.

2 De Duve examines what happens when the antinomy of taste is reworded from 'Thesis: a judgement of taste is not based on concepts' and 'Antithesis: a judgement of taste is based on concepts' to 'Thesis. Art is not a concept' and 'Antithesis. Art is a concept' (de Duve 1996: 304). This is the first step in his attempt to establish the questionable claim that the rephrased antinomy amounts to the proposition that "the word "art" conflates genius and taste and refers both to an "inexponible" aesthetic idea and to an "indemonstrable" rational idea' (de Duve 1996: 314). Genius, taste, aesthetic ideas and rational ideas all have their place within Kant's theory of judgement, and so it is by no means clear how rephrasing the antinomy gets de Duve to the point where he can claim 'conflation'.

3 I am not the first to argue that the Critique of the Power of Judgment contains theses which can help us to think about art after modernism. Diarmuid Costello argues that the 'imaginative engagement with ideas' contained within Kant's concept of an aesthetic idea may be applied to create an 'aesthetics of conceptual art', that is, to give an account of 'the way in which much conceptual art engages the mind' (Costello 2007: 103-4). My account is sympathetic to Costello's claim that works of conceptual art can be received as expressions of aesthetic ideas, including the prompting of much thought 'to which no determinate thought whatsoever ... can be adequate' (CPJ, 5: 313). However, beyond this, our ambitions diverge. Costello addresses a particular model of conceptual art which presents itself as a practice that is opposed to any kind of aesthetic appreciation, whereas I am looking at contemporary art (or postconceptual art in Osborne's idiom), and considering how purposiveness within Kant's theory of judgement might illuminate its interpretation.

4 The precise status of this analogy for the structure of Kant's architectonic has been the subject of much scholarship. A principal issue is whether his theory of aesthetic judgement can be regarded as complete 
and coherent on its own terms or whether it requires an analogical link to his moral philosophy. See e.g. Allison (2001) and Guyer (1997), who argue that the universal validity of aesthetic judgement is fully accounted for in epistemological terms, and Genova (1970), Gotshalk (1967) and Rogerson (1982), who argue that the universality is in fact supplied by an analogical link to morality.

5 The gallery display caption for Ceal Floyer's Monochrome Till Receipt (White), from the Tate website, is given here. Although it is not stated, the text in italics appears to be a quotation from the artist. There is no author credit but the date is given as 2016. The caption can be found at www.tate.org.uk/art/ artworks/floyer-monochrome-till-receipt-white-t12894 (accessed 30 April 2021):

A shopping receipt may seem like a strange thing to put on an art gallery wall. How can this be art? Rather than making a painting or sculpture, there are many artists (like Ceal Floyer here) who create art from everyday things. She would like you to think about the idea behind the art, rather than what it looks like. Take a closer look at the receipt. You will see that it is a list of objects bought from the supermarket that are all white. Imagine the objects and their whiteness and think about why this might be in a display about colour. Is white a colour?

It's actually a funny process... How many packets I've opened to check [the contents are white] and then not bought. But basically it should equal or come close to a picture of white.

6 I am grateful to anonymous reviewers arranged by the journal, and to participants at the 'Kant, Aesthetics and Contemporary Art' conference hosted by Cardiff University in October 2020, for comments on earlier versions of this article.

\section{References}

Agamben, Giorgio (2009) 'What is the Contemporary?' In Werner Hamacher (ed.), What is an Apparatus? Trans. David Kishik and Stefan Pedatella (Stanford, CA: Stanford University Press), 39-56.

Allison, Henry E. (2001) Kant's Theory of Taste. Cambridge: Cambridge University Press.

Batteux, Charles (2015) The Fine Arts Reduced to a Single Principle. Trans. James O. Young. Oxford: Oxford University Press. (Original work published 1746.)

Costello, Diarmuid (2007) 'Kant after LeWitt: Towards an Aesthetics of Conceptual Art'. In Peter Goldie and Elisabeth Schellekens (eds), Philosophy and Conceptual Art (Oxford: Oxford University Press), 92-116.

Danto, Arthur C. (1964) 'The Artworld'. Journal of Philosophy, 61, 571-84.

- (1981) The Transfiguration of the Commonplace. Cambridge, MA: Harvard University Press.

(2000) 'Marcel Duchamp and the End of Taste: A Defence of Contemporary Art'. Tout-Fait: The Marcel Duchamp Studies Online Journal, 1(3). www.toutfait.com/issues/issue_3/News/Danto/danto.html (accessed 29 May 2021).

De Duve, Thierry (1996) Kant After Duchamp. Cambridge, MA: MIT Press.

Gadamer, Hans-Georg (1989) Truth and Method, 2nd edn. Trans. Joel Weinsheimer and Donald G. Marshall. London: Sheed \& Ward. (Original work published 1960.)

Genova, A. C. (1970) 'Kant's Complex Problem of Reflective Judgement', Review of Metaphysics, 23, 452-80. Ginsborg, Hannah (1997). 'Lawfulness without a law: Kant on the Free Play of the Imagination and Understanding'. Philosophical Topics, 25, 37-82.

Gotshalk, D. W. (1967) 'Form and Expression in Kant's Aesthetics'. British Journal of Aesthetics, 7, 250-60. Greenberg, Clement (1986) ‘Avant-Garde and Kitsch'. In John O’Brian (ed.), Clement Greenberg: The Collected Essays and Criticism, vol. 1. Perceptions and Judgments (1939-1944) (Chicago: University of Chicago Press), 522. (Work originally published 1939.)

Guyer, Paul (1997) Kant and the Claims of Taste. 2nd edn. Cambridge: Cambridge University Press.

Kant, Immanuel (1987) Critique of [the Power of] Judgment. Trans. Werner S. Pluhar. Indianapolis: Hackett. References to this work take the form 'CPJ: 5:' with numbers corresponding to the pagination of the original Akademie edition. Numbers followed by an inverted comma, e.g. 223', refer to the pagination of the 'First Introduction of the Critique of Judgment' included in the Pluhar translation. In one case, section numbers are given: $\S \S 16-17$.

Kidd, Stephen E. (2019) Play and Aesthetics in Ancient Greece. Cambridge: Cambridge University Press.

Nietzsche, Friedrich (1999) The Birth of Tragedy and Other Writings. Ed. Raymond Geuss and Ronald Speirs, trans. Ronald Speirs. Cambridge: Cambridge University Press. (Original work published 1872.) 
Osborne, Peter (2013) Anywhere or Not at All: Philosophy of Contemporary Art. London: Verso.

Rajchman, John (2011) 'The Contemporary: A New Idea?' In Armen Avanessian and Luke Skrebowski (eds), Aesthetics and Contemporary Art (Berlin: Sternberg Press), 125-44.

Rogerson, Kenneth F. (1982) 'The Meaning of Universal Validity in Kant's Aesthetics', Journal of Aesthetics and Art Criticism, 40, 301-8.

Rush Jr., Fred L. (2001) 'The Harmony of the Faculties'. Kant-Studien, 92, 38-61.

Schiller, Friedrich (1993) 'Letters on the Aesthetic Education of Man'. In Walter Hinderer and Daniel 0. Dahlstrom (eds), Essays (New York: Continuum), 86-178. (Original work published 1795.)

Smith, Terry (2006) 'Contemporary Art and Contemporaneity', Critical Inquiry, 32, 681-707.

Spariosu, Mihai (1989) Dionysus Reborn: Play and the Aesthetic Dimension in Modern Philosophical and Scientific Discourse. Ithaca, NY: Cornell University Press.

Sutton-Smith, Brian (1997) The Ambiguity of Play. Cambridge, MA: Harvard University Press.

Cite this article: Cazeaux, C. (2021). Judging Contemporary Art with Kant. Kantian Review 26, 635-652. https://doi.org/10.1017/S1369415421000364 